\title{
Left atrial volume index and aortic stiffness index in adult hemodialysed patients - link between compliance and pressure mediated by endothelium dysfunction; a cross-sectional study
}

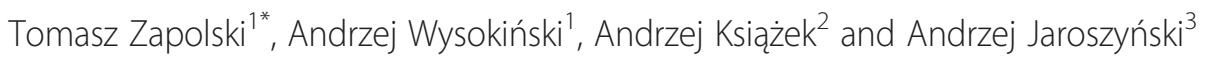

\begin{abstract}
Background: This study was performed to investigate the relationship between elastic properties of aorta and left atrium volume index (LAVI) in hemodialyzed (HD) patients.

Methods: Study group was consisted of 73 patients (age 51,6 \pm 7,6 years) treated by hemodialysis. In all patients standard echocardiography was performed. Aortic stiffness index (ASI) was calculated using formula: ASI = log (SBP/DBP)/ [(Aomax-Aomin)/Aomin]. LAVI was calculated according to the formula: $L A V I=[\pi / 6 \times(L A m a x \times L A s h o r t \times L A l o n g)] / m^{2}$. Additionally several indices were calculated: left ventricle mass (LVM), left ventricle mass index (LVMI), midwall fractional shortening (mFS), endsystolic stress (ESS), mFS/ESS. Additionally the laboratory parameters including lipidogram, troponin $\mathrm{T}(\mathrm{c} T \mathrm{nT})$, NT-proBNP and asymmetric dimethylarginine (ADMA) were measured.

Results: The ASI was strong and significantly correlated with left atrium volume (LAV) and LAVI (respectively: 0,601; $p<0,001$ and 0,598; $p<0,001$ ). The ASI was independently and markedly associated with ADMA, CTnT, CRP, T-chol, and LDL-chol. The LAVI was independently and significantly correlated with NT-proBNP and CTnT.

Conclusions: There is correlation between ASI and ADMA, marker of endothelium dysfunction. There is also association between LAVI and NT-proBNP, signs of elevated left atrium pressure. The strong correlation between ASI and LAVI, improved by associations of specific biochemical markers with these echocardiographic indices, suggests there is the link between elastic properties of aorta and left atrium pressure in hemodialysed patients mediated by endothelial dysfunction.
\end{abstract}

Keywords: Left atrium volume index, Aortic stiffness, NT-pro BNP, Asymmetric dimethylarginine, End-stage renal disease, Hemodialysis

\section{Background}

Cardiovascular complications are the main cause of death in patients with end-stage renal disease (ESRD) on renal replacement therapy [1]. Most of recent advances in the explanation of cardiovascular complications related to ESRD have concentrated on atherosclerosis, and much less studies have been dedicated to evaluate the mechanism related to hemodynamic changes occurred as a consequence of renal failure and renal

\footnotetext{
* Correspondence: zapolia@wp.pl

${ }^{1}$ Chair and Department of Cardiology, Medical University of Lublin, Lublin, Poland

Full list of author information is available at the end of the article
}

replacement interventions. Morphological and functional alterations in response to the overload of pressure and volume characteristic for ESRD are named as uremic cardiomyopathy.

Left atrium (LA) enlargement is a hitherto overlooked component of the complex echocardiographic alterations that are observed in ESRD. In individuals with ESRD, left atrial volume (LAV) is independently associated with angiographically significant coronary artery disease, history of stroke, carotid intima-media thickness and signs of inflammation such as high concentration of hs-CRP [2]. Left atrium volume is adjusted to body surface area and expressed as left atrium volume index 
(LAVI). It has been postulated to use in ESRD LAVI as a potent biomarker for risk stratification and risk monitoring in patients with ESRD [3].

Because the LA is exposed to left ventricle filling pressures through the open mitral orifice during diastole, its size is influenced by the same factors that determine diastolic filling pressure. The diastolic dysfunction of the left ventricle is a common finding among patients with ESRD. One of the most important factors influencing left ventricle function independent of blood pressure is aortic stiffness [4].

Atherosclerosis was regarded as a combination of two major separate diseases: atherosis and sclerosis. Sclerosis component depends on deterioration of aortic elastic properties and is called aortic stiffness. The stiffness of the aorta influences aortic conduit function causes pressure elevation and abnormal pressure pattern that increases the afterload of the left ventricle. In that way may induce left ventricle hypertrophy and alter on left ventricle diastolic and systolic function. It is well known that aortic stiffness is an independent predictor of allcause and cardiovascular mortality in different group of patients [5] including patients who require renal replacement therapy [6].

Endothelial dysfunction is a crucial precursor of the development of cardiovascular disease. The endothelium maintains the balance between vasoconstriction and vasodilatation. The role of the endothelium in controlling the vascular tone, especially vasodilatation, has been shown via the endothelial-derived nitric oxide (NO) [7]. Decreased NO production has also been linked to progression of renal dysfunction [8].

\section{Aim}

This study was performed to investigate the relationship between elastic properties of aorta and LAVI in hemodialised (HD) patients. Moreover the relationship between these functional and morphological parameters and selected biochemical markers was assessed.

\section{Methods}

\section{Clinical characterization of studied groups}

Study group was consisted of 73 patients (35 women and 38 men in age of $51,6 \pm 7,6$ years) treated by hemodialysis for mean time of $78,71( \pm 41,04)$ months. Hemodialysis were performed three times a week using devices as: Fresenius 4008B/S (Fresenius medical care, Bad Homburg, Germany) and Gambro AK95S (Gambro, Lund, Sweden). Bicarbonate dialysate containing (in millimoles per litre) 32 bicarbonate, 136-138 sodium, 2.5-4.0 potassium, 1.0 magnesium and 1.25 or 1.5 calcium was used in all HD patients. The mean time of hemodialysis session was $4.09 \pm 0.11 \mathrm{~h}$. The diffusive technique was applied in all cases. During hemodialysis, no medication was applied except heparin. All patients were hemodialysed for $>6$ months and were clinically stable. Out of $73 \mathrm{HD}$ patients, $46(60,2 \%)$ were taking angiotensin-converting enzyme inhibitors/angiotensin receptor blockers, 41 (56,2\%) beta-blockers, 44 (60,3\%) calcium blockers and $24(32,9 \%)$ statins.

The causes of ESRD in this group were as follow: glomerulonephritis - 32(43,8\%), diabetes mellitus - 11 (15,1\%), chronic tubulo-interstitial nephritis - 3(4,1\%), obstructive nephropathy - 5(6,8\%), hypertonic nephropathy $-3(4,1 \%)$, polycystic kidney disease $-4(5,5 \%)$ and unknown/uncertain - 15(20,5\%).

\section{Control group}

The control group comprised of 57 volunteers (27 women and 30 men) in age of $51,9 \pm 7,1$ years of comparable to study group clinical characterization, except that they didn't suffer from ESRD. They have had no abnormalities detected by physical examination, ECG, chest X-ray and laboratory analysis.

\section{Echocardiography}

In all patient and control subjects standard transthoracic echocardiographic examination was performed using 2,5-3,5 MHz transducer (HP Sonos 7500, Hewlett Packard, Bloomfield, CT, USA) by the cardiologist, who was blinded to the clinical data of the study subjects. All echocardiographic measurements were done according to the guidelines of the American Society of Echocardiography [9]. To exclude the influence of extracellular volume condition on systemic hemodynamic, echocardiographic examination was performed during first 60 minutes after a single hemodialysis session.

The following a two-dimensionally guided M-mode echocardiographic parameters were recorded: interventricular endsystolic septum diameter (IVSSd [cm]), interventricular septum enddiastolic diameter (IVSDd $[\mathrm{cm}]$ ), posterior wall systolic diameter (PWSd $[\mathrm{cm}]$ ), posterior wall diastolic diameter (PWDd $[\mathrm{cm}]$ ), left ventricle enddiastolic diameter (LVEDd [cm]), left ventricle endsystolic diameter (LVESd $[\mathrm{cm}]$ ), left atrium maximal diameter (LAmax $[\mathrm{cm}]$ ), aortic maximal diameter (Aomax $[\mathrm{cm}]$ ), aortic minimal diameter (Aomin $[\mathrm{cm}]$ ). The dimensions of the aorta were recorded in M-mode $3 \mathrm{~cm}$ above the aortic valve from a parasternal long axis view. The Aomax (systolic diameter) was measured at the time of aortic valve maximal opening. The Aomin (diastolic diameter) was recorded at the peak of the QRS complex. Inner aortic diameters were measured with a caliper in systole and diastole as the distance between the trailing edge of the anterior aortic wall and the leading edge of the posterior aortic wall [10]. In 4-CH presentation were additionally recorded: left atrium short diameter (LAshort $[\mathrm{cm}]$ ), left atrium 
longitudinal diameter (LAlong $[\mathrm{cm}]$ ), left atrium surface (LAS $\left.\left[\mathrm{cm}^{2}\right]\right)$ and left atrium circumference (LAC $\left.[\mathrm{cm}]\right)$. Consequently several standard indices were calculated according to American Society of Echocardiography recommendations [11] such as: left ventricle stroke volume $(\mathrm{SV}[\mathrm{ml}])$, stroke index (SI $[\mathrm{n}])$, cardiac output (CO $[1 / \mathrm{min}])$, cardiac index $\left(\mathrm{CI}\left[\mathrm{l} / \mathrm{min} / \mathrm{m}^{2}\right]\right)$, ejection fraction (EF [\%]), fractional shortening of left ventricle (FS [\%]). Using previously measured parameters the most important for present study indices were calculated according to formulas:

- Left ventricle mass (LVM [g]): LVM = 1,04x[(IVSDd + PWDd + LVEDd $\left.)^{3}\right]-13,6 \mathrm{~g}$

- Left ventricle mass index (LVMI $\left.\left[\mathrm{g} / \mathrm{m}^{2}\right]\right)$ : LVMI $=$ LVM/BSA

- Endsystolic stress $\left(\mathrm{ESS}\left[10^{3} \mathrm{dyn} / \mathrm{cm}^{2}\right]\right)$ : ESS = 0,334xSBPxLVESd/PWSdx (1 + PWSd/LVESd),

- Midwall fractional shortening (mFS [n]): $\mathrm{mFS}=$ [(LVEDd + PWSd/2 + IVSSd/2)-(LVESd + Hs/2)/ (LVEDd + PWSD/2 + IVSSd/2)]x100; where $\mathrm{Hs}=\mathrm{IVSSd}+\mathrm{PWSd}$,

- Ratio $\mathrm{mFS} / \mathrm{ESS}[\mathrm{n}]$,

- Left atrium volume (LAV[ml]): LAV = LAVI= $\pi / 6 x$ (LAmaxxLAshortxLAlong) [12] (Figure 1),

- Left atrium volume index (LAVI $\left[\mathrm{ml} / \mathrm{m}^{2}\right]$ ): $\mathrm{LAVI}=\mathrm{LAV} / \mathrm{m}^{2}$

- Aortic stiffness index (ASI [n]): ASI $=\log$ [(SBP/DBP)/(Aomax-Aomin)]/Aomin [10] (Figure 2).

Left ventricle hypertrophy was defined by a LVMI of $>134 \mathrm{~g} / \mathrm{m}^{2}$ in men or $>110 \mathrm{~g} / \mathrm{m}^{2}$ in women.

Moreover pulsed Doppler derived parameters were measured such as: maximal velocity of early diastolic transmitral flow $(E[\mathrm{~cm} / \mathrm{s}])$, maximal velocity of late diastolic transmitral flow $(\mathrm{A}[\mathrm{cm} / \mathrm{s}])$, isovolumetric relaxation time (IVRT [ms]), maximal systolic velocity in pulmonary veins $(\mathrm{S}[\mathrm{cm} / \mathrm{s}])$, maximal diastolic velocity in pulmonary veins $(\mathrm{D}[\mathrm{cm} / \mathrm{s}])$. Consequently ratios of $\mathrm{E} / \mathrm{A}$ and S/D were calculated. Diastolic dysfunction was recognized accordingly to recommendation of Canadian Cardiovascular Society [13]. Patients with restrictive spectrum were not included to this study.

The most important for this study echocardiographic indices were: LAVI and ASI. Patient from HD group were divided and compared using mean values of mentioned indices as cut-off values.

\section{Anthropometry, pressure and laboratory measurements}

Body surface area was calculated according to formula: BSA $\left(\mathrm{m}^{2}\right)=0.0235 \mathrm{x}$ height $(\mathrm{cm})^{0.42246} \mathrm{x}$ weight $(\mathrm{kg})^{0.51456}$ [14].

The systolic (SBP) and diastolic (DBP) pressures were obtained using electronic sphygmomanometer (Omron 705 CP, Omron, Kyoto, Japan). The brachial artery blood pressure measurement was made with the subjects remaining in the left lateral decubitus position in darkened, quiet room. While obtaining ascending aorta diameters by echocardiography, blood pressure in the right upper arm was simultaneously measured. Mean blood pressure (MBP) was calculated by the formula: $\mathrm{MBP}=1 / 3 \mathrm{SBP}+2 / 3 \mathrm{DBP}$. Moreover the mean heart rate calculated from the consecutive 10 beats was recorded.

The following standard parameters were measured by automated analyzer (ADVIA Centaur analyzer, Bayer Health-Care Diagnostics, Tarrytown, NY, USA): hemoglobin $[\mathrm{g} / \mathrm{dl}]$, sodium $[\mathrm{mmol} / \mathrm{l}]$, potassium $[\mathrm{mmol} / \mathrm{l}]$, calcium $[\mathrm{mmol} / \mathrm{l}]$, phosphorus $[\mathrm{mmol} / \mathrm{l}], \mathrm{Ca} \times \mathrm{P}$ score $\left[\mathrm{mg}^{2} / \mathrm{dl}^{2}\right]$, creatinine $[\mu \mathrm{mol} / \mathrm{l}]$, glomerular filtration rate

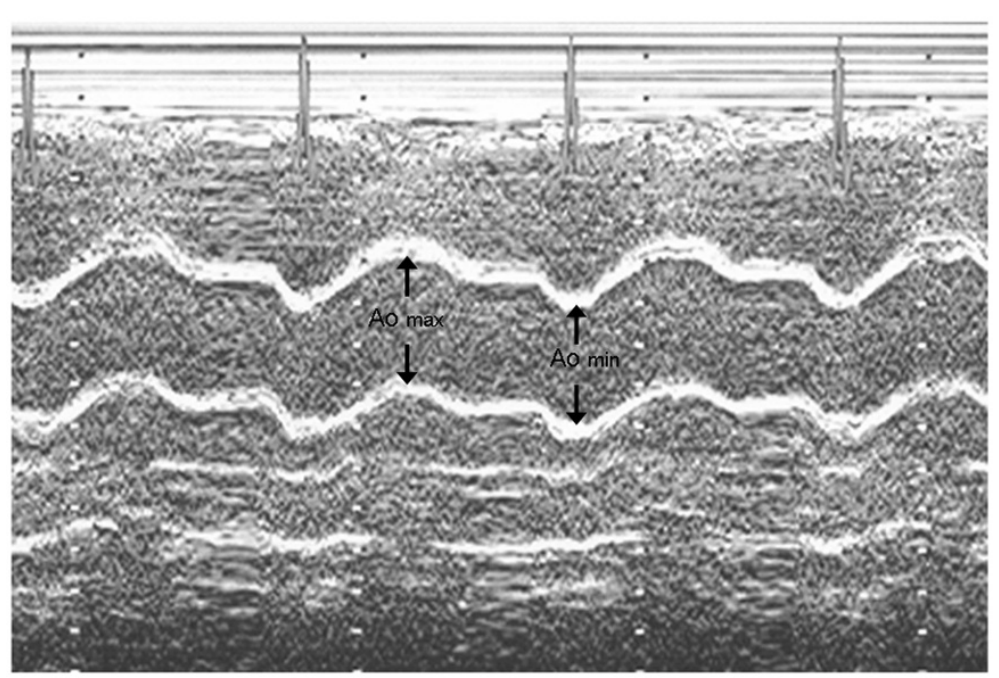

Figure 1 The measurement of diameters needed for ASI calculation. 


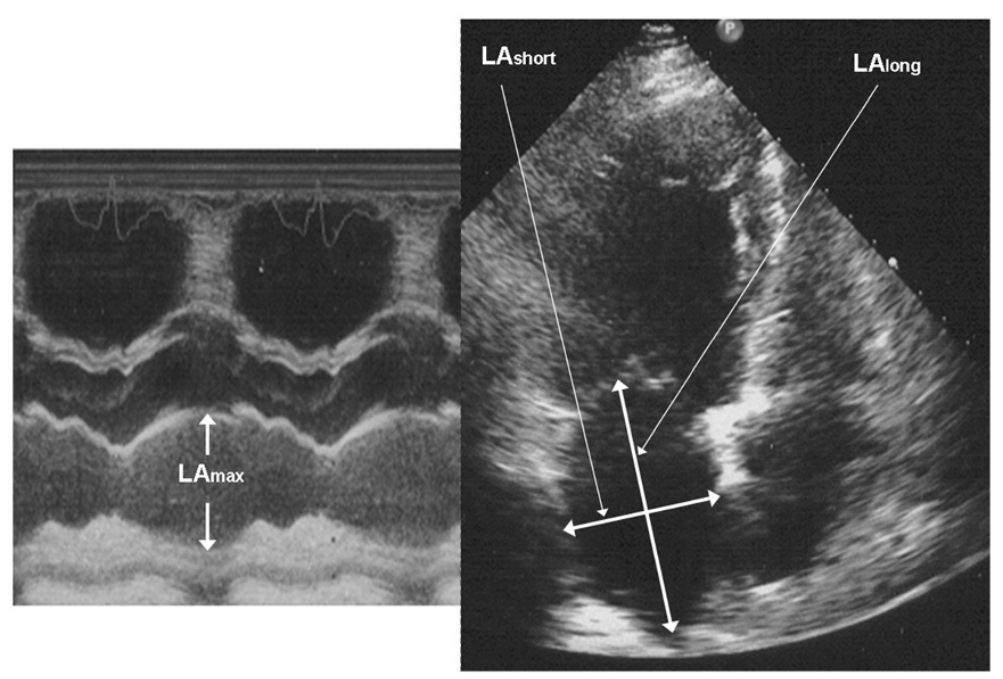

Figure $\mathbf{2}$ The measurement of diameters needed for LAVI calculation.

(GFR) $\left[\mathrm{ml} / \mathrm{min} / 1,73 \mathrm{~m}^{2}\right]$, urea $[\mathrm{mg} / \mathrm{l}]$, uric acid $[\mathrm{mg} / \mathrm{dl}]$, protein $[\mathrm{g} / \mathrm{l}]$, albumin $[\mathrm{g} / \mathrm{l}]$, high sensivity C-reactive protein (hs-CRP) $[\mathrm{mg} / \mathrm{ml}]$, fibrinogen $[\mathrm{g} / \mathrm{l}]$, total cholesterol (T-chol) [mg/dl], HDL-cholesterol (HDL-chol) [mg/dl], triglycerides (TGC) [mg/dl]. LDL-cholesterol (LDL-chol) $[\mathrm{mg} / \mathrm{dl}]$ was calculated using the Friedewald equation: LDL-chol $=$ T-chol - HDL-chol $-(\mathrm{TGC} / 5)$. GFR was calculated from the modification of diet in renal disease $\left(\right.$ MDRD) formula: GFR $=186 x$ serum creatinine $^{-1.154} \mathrm{x}$ age $^{-0.203} \times \mathrm{F}$, where $\mathrm{F}=1$ in men and $\mathrm{F}=0,742$ in women. Cardiac troponin $\mathrm{T}(\mathrm{cTnT})[(\mu \mathrm{g} / \mathrm{l}]$ in plasma was measured by the electrochemiluminescence immunoassay (Elecsys 2010 analyser, Roche Diagnostics Gmb, Mannheim, Germany) with the detection limit of $0,01 \mu \mathrm{g} / \mathrm{l}$. NT-proBNP $[\mathrm{fmol} / \mathrm{ml}]$ in plasma was measured by the enzyme-linked immunosorbent assay - ELISA method (Biomedica, Bratislava, Slovakia) with the detection range between $0-640 \mathrm{fmol} / \mathrm{ml}$. Asymmetric dimethylarginine (ADMA) $[\mu \mathrm{mol} / \mathrm{l}]$ was measured by immunoenzymatic method - EIA (ALPCO Diagnostics, Windham, New Hampshire, USA) with the detection range between $0,05-3,0 \mu \mathrm{mol} / \mathrm{l}$ and reference range for healthy population of $0,4-0,75 \mu \mathrm{mol} / \mathrm{l}$ ).

The study protocol was approved by a university ethics review board. The investigation conforms with the principles outlined in the Declaration of Helsinki.

\section{Reproducibility}

Intraobserver variability for ASI and LAVI measurements were assessed. For intraobserver variability, a sample of 10 ASI and LAVI measurements was randomly selected and examined by the same observer in two different days after sessions of hemodialysis. Intraclass correlation coefficients for the same observer were calculated [15].

\section{Statistical analysis}

Statistical analysis was carried out on an IBM PC using of a standard statistical package (SPSS for Windows Version 12.0; SPSS INC, Chicago, Illinois). Data were expressed as mean \pm SD (parametrically distributed continuous variables) and percentage (categorical variables). The statistical significance of the differences between HD patients and control group means were compared by unpaired Student's t-test, the Mann-Whitney test, or chisquare test with Yates correction. Pearson's test was used to calculate correlation coefficients. Multiple stepwise regression analysis was performed to estimate the potential influence of various laboratory, biochemical factors and both SBP and MBP on LAVI and ASI. The following independence parameters were entered into the model: hemoglobin, sodium, potassium, calcium, phosphorus, $\mathrm{Ca}$ $\mathrm{x}$ P score, creatinine, urea, total protein, albumin, hs-CRP, T-chol, LDL-chol, HDL-chol, TGC, cTnT, NT-proBNP, ADMA. Probability values of $<0,05$ were accepted as significant.

\section{Results}

\section{Baseline comparison}

Clinical characteristics and laboratory measurements of the study population and control group are listed in Table 1 . The heart rate and SBD, MBP were significantly higher among HD patients compared to controls, whereas DBP did not differ between study groups and control group.

Baseline echocardiographic characteristic of the studied patients and controls are shown in Table 2. All diameters derived from a two-dimensionally guided M-mode echocardiography were significantly greater either in HD patients when compared to control group. Similarly parameters concerning left ventricle systolic and diastolic 
Table 1 Pressure, heart rate and biochemical measurements collected in studied patients

\begin{tabular}{|c|c|c|c|}
\hline Parameter & HD & Controls & $p$ \\
\hline Mean heart rate[beats/min] & $74,40( \pm 10,81)$ & $73,47( \pm 4,87)$ & 0,402 \\
\hline Systolic blood pressure[mmHg] & $139,4( \pm 22,1)$ & $123,7( \pm 8,15)$ & $<0,001$ \\
\hline Diastolic blood pressure[mmHg] & $72,98( \pm 12,02)$ & $74,15( \pm 9,09)$ & 0,387 \\
\hline Mean blood pressure[mmHg] & $95,07( \pm 14,28)$ & $90,60( \pm 3,74)$ & $<0,001$ \\
\hline Hemoglobin[g/dl] & $11,98( \pm 1,46)$ & $13,89( \pm 0,81)$ & $<0,001$ \\
\hline Sodium[mmol/l] & $138,5( \pm 2,5)$ & $138,4( \pm 1,7)$ & 0,583 \\
\hline Potassium[mmol/l] & $5,698( \pm 0,735)$ & $4,301( \pm 0,278)$ & $<0,001$ \\
\hline Calcium[mmol/l] & $2,259( \pm 0,190)$ & $2,364( \pm 0,041)$ & 0,007 \\
\hline Phosphorus[mmol/l] & $1,991( \pm 0,541)$ & $1,09( \pm 0,06)$ & $<0,001$ \\
\hline $\mathrm{Ca} \times \mathrm{P}\left[\mathrm{mg}^{2} / \mathrm{dl}^{2}\right]$ & $55,86( \pm 14,64)$ & $31,28( \pm 2,65)$ & $<0,001$ \\
\hline Creatinine $[\mu \mathrm{mol} / \mathrm{l}]$ & $777,0( \pm 223,6)$ & $\pm 9,79)$ & $<0,001$ \\
\hline Urea[mmol/l] & $24,39( \pm 7,22)$ & $4,233( \pm 0,897)$ & $<0,001$ \\
\hline Total protein[g/l] & $68,3( \pm 0,52)$ & $72,01( \pm 0,28)$ & $<0,001$ \\
\hline Albumin[g/l] & $3,935( \pm 0,356)$ & $4,636( \pm 0,204)$ & $<0,001$ \\
\hline $\mathrm{Hs}-\mathrm{CRP}[\mathrm{mg} / \mathrm{l}]$ & $6,248( \pm 0,23)$ & $0,45( \pm 0,09)$ & $<0,001$ \\
\hline T-chol[mg/dl] & $189,7( \pm 43,75)$ & $190,5( \pm 22,32)$ & 0,437 \\
\hline LDL-chol[mg/dl] & $114,3( \pm 30,61)$ & $112,0( \pm 20,43)$ & 0,504 \\
\hline HDL-chol[mg/dl] & $41,51( \pm 16,19)$ & $56,7( \pm 11,24)$ & $<0,001$ \\
\hline$\overline{\mathrm{TGC}[\mathrm{mg} / \mathrm{dl}]}$ & $170,8( \pm 74,89)$ & $109,1( \pm 38,9)$ & $<0,001$ \\
\hline $\mathrm{cTnT}[(\mu \mathrm{g} / \mathrm{l}]$ & $0,05( \pm 0,011)$ & $<0.01$ & $<0,001$ \\
\hline NT-proBNP[fmol/ml] & $187,7( \pm 96,2)$ & $22,71( \pm 17,23)$ & $<0,001$ \\
\hline ADMA[ $[\mu \mathrm{mol} / /]$ & $1,031( \pm 0,193)$ & $0,772( \pm 0,253)$ & $<0,001$ \\
\hline
\end{tabular}

functions were markedly differ between study group and control group. SV and SI were decreased whereas $\mathrm{CO}$ and CI did not differ between them and controls. LVM and its index were significantly higher in HD patients. Patients exhibited significantly greater aortic stiffness expressed by higher value of ASI than in control group. Parameters concerning LA were also greater in HD patients than in control.

The current study showed a significant correlation between the ASI and LAVI (Figure 3). We have also indicated a close, significant, relationship between the ASI and the indices of left ventricular systolic function as $\mathrm{mFS} / \mathrm{ESS}$, ESS and left ventricular diastolic function as E/A ratio, IVRT and S/D ratio. ASI also positively correlated with indicators of left ventricular hypertrophy as follows: LVM and LVMI (Table 3).

\section{Cut-off values of selected echocardiographic indices}

After the division into subgroups using mean LAVI value of $36,29 \mathrm{ml} / \mathrm{m}^{2}$, calculated for whole HD group, us cut-off value, in subgroups of LAVI < cut-off value were 38 patients $\left(\mathrm{LAVI}=33,81 \pm 7,93 \mathrm{ml} / \mathrm{m}^{2}\right)$ and in subgroup of LAVI > cut-off value were 35 persons (LAVI 38,83 \pm $9,37 \mathrm{ml} / \mathrm{m}^{2}$ ). Similarly study group was divided into two subgroups due to mean calculated value ASI of 5,61 as a
Table 2 Echocardiographic data

\begin{tabular}{|c|c|c|c|}
\hline Parameter & HD & Controls & $\mathbf{P}$ \\
\hline \multicolumn{4}{|l|}{ Diameters of the heart } \\
\hline LVEDd[cm] & $5,14( \pm 0,59)$ & $4,62( \pm 0,44)$ & $<0,001$ \\
\hline LVESd[cm] & $3,23( \pm 0,54)$ & $2,91( \pm 0,36)$ & $<0,001$ \\
\hline $\mathrm{PWDd}[\mathrm{cm}]$ & $1,24( \pm 0,24)$ & $0,91( \pm 0,05)$ & $<0,001$ \\
\hline $\mathrm{PWSd}[\mathrm{cm}]$ & $1,60( \pm 0,23)$ & $1,29( \pm 0,06)$ & $<0,001$ \\
\hline $\mathrm{IVSDd}[\mathrm{cm}]$ & $1,44( \pm 0,24)$ & $0,94( \pm 0,06)$ & $<0,001$ \\
\hline IVSSd[cm] & $1,67( \pm 0,28)$ & $1,18( \pm 0,07)$ & $<0,001$ \\
\hline \multicolumn{4}{|l|}{ Parameters of LV mass } \\
\hline LVM[g] & $253,9( \pm 92,53)$ & $154,6( \pm 32,6)$ & $<0,001$ \\
\hline LVMI $\left[\mathrm{g} / \mathrm{m}^{2}\right]$ & $146,5( \pm 45,18)$ & $97,14( \pm 26,35)$ & $<0,001$ \\
\hline LVH[\%] & 64,8 & 0 & $<0,001$ \\
\hline \multicolumn{4}{|l|}{ Parameters of heart stroke } \\
\hline $\mathrm{SV}[\mathrm{ml}]$ & $70,39( \pm 15,34)$ & $79,46( \pm 13,03)$ & 0,009 \\
\hline $\mathrm{SI}\left[\mathrm{ml} /\right.$ beat $\left./ \mathrm{m}^{2}\right]$ & $42,08( \pm 11,19)$ & $45,93( \pm 4,22)$ & 0,001 \\
\hline $\mathrm{CO}[1 / \mathrm{min}]$ & $5,49( \pm 0,81)$ & $5,73( \pm 0,49)$ & 0,106 \\
\hline $\mathrm{Cl}\left[\mathrm{l} / \mathrm{min} / \mathrm{m}^{2}\right]$ & $3,24( \pm 0,53)$ & $3,31( \pm 0,32)$ & 0,126 \\
\hline \multicolumn{4}{|c|}{ Parameters of systolic function } \\
\hline $\mathrm{EF}[\%]$ & $58,91( \pm 6,21)$ & $65,52( \pm 3,87)$ & $<0,001$ \\
\hline$\overline{\mathrm{FS}[\%]}$ & $31,54( \pm 5,83)$ & $38,9( \pm 4,302)$ & $<0,001$ \\
\hline $\mathrm{mFS[ \% ]}$ & $15,34( \pm 3,26)$ & $20,12( \pm 2,87)$ & $<0,001$ \\
\hline $\mathrm{mFS} / \mathrm{ESS}[\mathrm{n}]$ & $0,186( \pm 0,056)$ & $0,218( \pm 0,043)$ & 0,002 \\
\hline \multicolumn{4}{|c|}{ Parameters of diastolic function } \\
\hline$E / A[n]$ & $0,979( \pm 0,256)$ & $1,371( \pm 0,135)$ & $<0,001$ \\
\hline IVRT[ms] & $109,1( \pm 22,73)$ & $76,53( \pm 14,04)$ & $<0,001$ \\
\hline $\mathrm{DT}[\mathrm{ms}]$ & $229,9( \pm 45,12)$ & $179,3( \pm 27,41)$ & 0,001 \\
\hline $\mathrm{S} / \mathrm{D}[\mathrm{n}]$ & $1,49( \pm 0,268)$ & $1,22( \pm 0,181)$ & $<0,001$ \\
\hline Relaxation abnormalities[\%] & 43,66 & 1,75 & $<0,001$ \\
\hline \multicolumn{4}{|l|}{ Parameters of left atrium } \\
\hline $\mathrm{LAS}\left[\mathrm{cm}^{2}\right]$ & $23,59( \pm 5,1)$ & $19,35( \pm 3,44)$ & $<0,001$ \\
\hline $\mathrm{LAC}[\mathrm{cm}]$ & $19,5( \pm 4,58)$ & $16,32( \pm 3,07)$ & $<0,001$ \\
\hline LAmax $[\mathrm{cm}]$ & $4,3( \pm 0,59)$ & $3,53( \pm 0,27)$ & $<0,001$ \\
\hline $\mathrm{LAV}[\mathrm{ml}]$ & $62,52( \pm 21,3)$ & $36,82( \pm 14,76)$ & $<0,001$ \\
\hline $\mathrm{LAVI}\left[\mathrm{ml} / \mathrm{m}^{2}\right]$ & $36,29( \pm 10,92)$ & $20,64( \pm 6,77)$ & $<0,001$ \\
\hline \multicolumn{4}{|l|}{ Parameters of aorta } \\
\hline $\mathrm{ASI}[\mathrm{n}]$ & $5,51( \pm 1,32)$ & $3,07( \pm 1,09)$ & $<0,001$ \\
\hline
\end{tabular}

cut-off value. The first of these subgroups of ASI $<$ cutoff value consisted of 37 patients with ASI 4,15 $\pm 1,74$ and in second subgroup of ASI > cut-off value were 36 subjects with ASI 7,19 $\pm 1,62$. The comparison of subgroups created by cut-off values of LAVI and ASI with regarding to selected hemodynamic and laboratory data are shown in Table 4.

\section{Multiple stepwise regression analysis}

The ASI had been found independently and markedly associated with ADMA, cTnT, hs-CRP, T-chol, LDL-chol, but not with SBP and MBP in HD patients. Multiple 


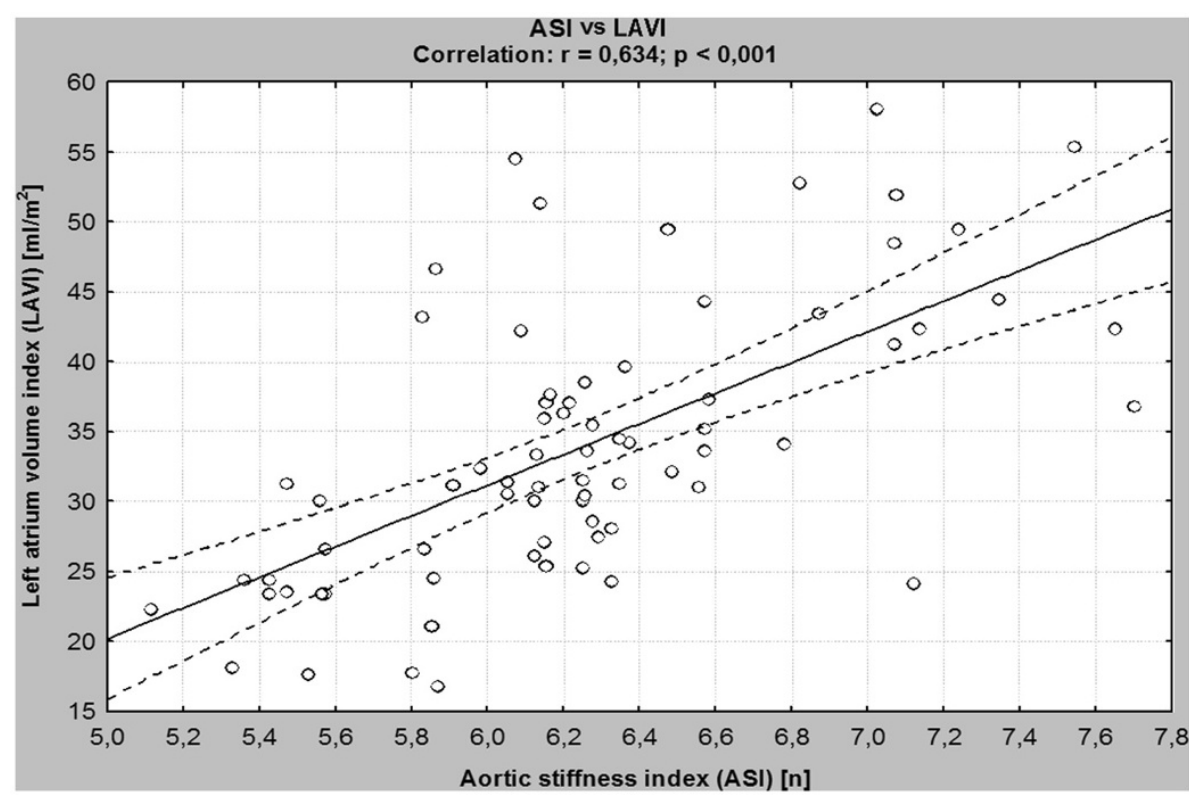

Figure 3 The association between ASI and LAVI.

stepwise regression analysis had been showed that the LAVI was independently associated with NT-proBNP and $\mathrm{cTnT}$ (Table 5).

\section{Reproducibility}

Intraclass correlation for intraobserver variability was good for ASI measurements: 0,88; 0,77-0,95; 95\% confidence interval. Intraclass correlations for intraobserver variability was also good for LAVI measurements: 0,85 ; 0,76-0,97; 95\% confidence interval.

\section{Discussion}

LAVI and laboratory and echocardiographic parameters Important observation of this study is that HD patients had greater LA dimension and therefore LAV and LAVI

Table 3 Correlations between ASI [n] and echocardiographic parameters

\begin{tabular}{|c|c|c|}
\hline Parameter & $\mathbf{R}$ & $\mathbf{P}$ \\
\hline LAV [ml] & 0,579 & $p<0,001$ \\
\hline LAVI $\left[\mathrm{ml} / \mathrm{m}^{2}\right]$ & 0,634 & $\overline{p<0,001}$ \\
\hline ESV [ml] & 0,336 & $p=0,024$ \\
\hline EDV [ml] & 0,372 & $p=0,008$ \\
\hline LVM [g] & 0,532 & $P=0,001$ \\
\hline LVMI $\left[\mathrm{g} / \mathrm{m}^{2}\right]$ & 0,543 & $p<0,001$ \\
\hline$E / A$ [n] & $-0,354$ & $p=0,009$ \\
\hline IVRT [msec] & 0,353 & $p=0,021$ \\
\hline S/D [n] & $-0,402$ & $p=0,004$ \\
\hline ESS [\%] & 0,442 & $p=0,002$ \\
\hline mFS/ESS [n] & $-0,532$ & $p<0,001$ \\
\hline
\end{tabular}

than control patients. These findings are important because it is well known that LAVI is an independent predictor of prognosis in HD patients providing information to traditional clinical and Doppler echocardiographic data [16]. We have adjusted LAV not by height, but by surface area. The adjustment to body size using height failed to nullify the gender influence on atrial size, unlike the adjustment to body surface area [17]. The diastolic dysfunction and increased LAV and LAVI in patients from hemodialysis group may in part be attributed to an increased LVMI as well as deteriorated elastic properties of the aorta.

In recent years, echocardiographic assessment of the LA and its relationship with cardiovascular risk have been revalued. LA size, particularly LAV has been recognized as a marker of diastolic dysfunction [18]. Current guidelines in the general population jointly issued by the American College of Cardiology, the American Heart Association, and the European Society of Cardiology consider the measurement of the LAV and LAVI as clinically relevant information [19]. Increased LAVI is a powerful predictor of mortality after acute myocardial infarction and provides prognostic information incremental to clinical data and conventional measure of left ventricle systolic and diastolic function [20]. LAVI is also useful index for prediction of adverse cardiovascular events and may predict first ischemic stroke and subsequent mortality [20]. Monitoring of left atrium size by echocardiography is also useful for predicting cardiovascular risk in patients with end-stage renal disease. Chan et al. [21] demonstrated that each $\mathrm{mm} / \mathrm{m}^{2}$ increase in indexed LA diameter was associated with a small but 
Table 4 The comparison of calculated cut-off value of ASI and LAVI to laboratory parameters

\begin{tabular}{|c|c|c|c|}
\hline Parameter & $\begin{array}{c}\text { ASI > cut-off value } \\
n=36\end{array}$ & $\begin{array}{c}\text { ASI < cut-off value } \\
n=37\end{array}$ & $\mathbf{P}$ \\
\hline ADMA[ $[\mu \mathrm{mol} / \mathrm{l}]$ & $1,134( \pm 0,201)$ & $0,881( \pm 0,169)$ & 0,002 \\
\hline $\mathrm{cTnT}[\mu \mathrm{g} / \mathrm{l}]$ & $0,068( \pm 0,016)$ & $0,043( \pm 0,09)$ & 0,001 \\
\hline CRP[g/l] & $6,92( \pm 0,51)$ & $5,57( \pm 0,21)$ & 0,007 \\
\hline Total chol(mg/dl) & $229,4( \pm 46,9)$ & $162,4( \pm 40,2)$ & 0,01 \\
\hline LDL-chol(mg/dl) & $128,2( \pm 33,5)$ & $101,1( \pm 27,3)$ & 0,02 \\
\hline NT-proBNP[fmol/ml] & $195,8( \pm 101,5)$ & $172,9( \pm 92,8)$ & 0,03 \\
\hline Creatinine $[\mu \mathrm{mol} / \mathrm{l}]$ & $792,0( \pm 229,9)$ & $762,4( \pm 218,8)$ & NS \\
\hline \multirow[t]{2}{*}{$\mathrm{Ca} \times \mathrm{P}\left[\mathrm{mg}^{2} / \mathrm{dl}^{2}\right]$} & $56,34( \pm 15,14)$ & $54,41( \pm 13,81)$ & NS \\
\hline & $\begin{array}{c}\text { LAVI > cut-off value } \\
n=35\end{array}$ & $\begin{array}{c}\text { LAVI < cut-off value } \\
\quad \mathrm{n}=38\end{array}$ & $\mathbf{P}$ \\
\hline $\mathrm{ADMA}[\mu \mathrm{mol} / \mathrm{l}]$ & $1,077( \pm 0,197)$ & $0,946( \pm 0,159)$ & 0,047 \\
\hline $\mathrm{CTnT}[\mu \mathrm{g} / \mathrm{l}]$ & $0,063( \pm 0,014)$ & $0,048( \pm 0,012)$ & 0,001 \\
\hline $\mathrm{CRP}[\mathrm{mg} / \mathrm{l}]$ & $6,520( \pm 0,54)$ & $5,905( \pm 0,29)$ & 0,03 \\
\hline Total chol[mg/dl] & $201,4( \pm 46,5)$ & $181,2( \pm 39,3)$ & NS \\
\hline LDL-chol[mg/dl] & $119,8( \pm 31,3)$ & $110,1( \pm 26,8)$ & NS \\
\hline NT-proBNP[fmol/ml] & $231,2( \pm 115,7)$ & $136,9( \pm 91,6)$ & 0,001 \\
\hline Creatinine $[\mu \mathrm{mol} / \mathrm{l}]$ & $789,1( \pm 231,4)$ & $767,2( \pm 207,4)$ & NS \\
\hline $\mathrm{Ca} \times \mathrm{P}\left[\mathrm{mg}^{2} / \mathrm{dl}^{2}\right]$ & $57,15( \pm 16,08)$ & $53,11( \pm 12,55)$ & NS \\
\hline
\end{tabular}

significant risk of increased cardiovascular mortality [21]. Changes in LAV can also predict incident cardiovascular events in dialysis patients independent of the corresponding baseline measurement and of left ventricular mass [3].

In the present study NT-proBNP plasma level was significantly elevated in HD group. In literature there are conflicting data on the influence of glomerular filtration rate on BNP and NT-proBNP levels in ESRD. Tagore et al. [22] suggested that unlike NT-pro BNP, plasma BNP level is relatively independent of GFR. Most authors suggest to use NT-proBNP when patients with ESRD are evaluated. However data on NT-proBNP in renal dysfunction are more concordant but were derived from populations that included patients with impaired

Table 5 Factors influencing ASI and LAVI estimated by multivariate stepwise regression analysis

\begin{tabular}{lccccc}
\hline \multirow{2}{*}{\begin{tabular}{l} 
dependent $\begin{array}{c}\text { HD group } \\
\text { variable }\end{array}$ \\
\cline { 2 - 6 }
\end{tabular}} & $\begin{array}{l}\text { independent } \\
\text { variables }\end{array}$ & $\mathbf{B}$ & $\begin{array}{c}\text { standard } \\
\text { error }\end{array}$ & $\boldsymbol{\beta}$ & $\mathbf{P}$ \\
\hline ASI & ADMA & 50,3 & 16,6 & 0,409 & 0,006 \\
\cline { 2 - 6 } & CTnT & 121,5 & 34,7 & 0,443 & $<0,001$ \\
\cline { 2 - 6 } & CRP & 4,92 & 1,83 & 0,281 & 0,002 \\
\hline Total chol & 0,805 & 0,237 & 0,340 & 0,003 \\
\hline LDL-chol & 1,427 & 0,428 & 0,329 & 0,004 \\
\cline { 2 - 6 } & NT-proBNP & 1,16 & 0,453 & 0,328 & 0,007 \\
\hline
\end{tabular}

left ventricle function or heart failure [23]. This explain why is so difficult to account fully for the effect of coexistent cardiac disease, left ventricle dysfunction and volume overload, all conditions usually observed among patients with ESRD.

Our study has revealed for the first time highly significant correlation between LAVI and NT-proBNP among HD patients. Association between these two parameters was already described, but in other clinical settings. Kim et al. [24] documented the correlation of LAVI and level of NT-proBNP in patients with heart failure and a preserved ejection fraction. The combination of both LAVI and NT-proBNP also is more useful to stratify risk of sudden cardiac death than other clinical echocardiographic or biochemical variable [25]. The combination of these two parameters should be considered for predicting sudden cardiac deaths in patients with ESRD. Further studies are needed to assess the possible clinical importance of association between LAVI and NTproBNP in such specific group of patients.

The higher values of LAVI with coexisting elevated plasma concentration of NT-proBNP may be a manifestation of so called cardio-renal syndrome [26]. In this clinical situation LA enlargement and higher NT-proBNP levels arising from heart disease, and greater preload which is partially caused by loss of elastic properties of aorta.

\section{ASI and laboratory and echocardiographic parameters}

We evaluated that ASI was significantly higher in patients with ESRD than in subjects without renal dysfunction. It is well known that aortic elastic properties are affected by the risk factors for atherosclerosis. The coexistence of atherosclerosis and ESRD suggests there is the link between these two diseases [27]. Atherosclerosis is regarded as a combination of two separate diseases: atherosis and sclerosis. The aortic stiffness reflects sclerotic component and means mechanical properties of aortic wall. Calcium overload, which is characteristic feature for ESRD patients, and also observed in our patients especially before hemodialysis, is associated with aortic stiffening. Vascular calcification is detected either in the tunica intima or in the tunica media. Calcification in the intima is characteristic of most stages of atherosclerosis. Medial calcification is particularly common in patients with ESRD and may occur independently of atherosclerosis. Medial wall calcification increases vascular stiffness and reduces arterial compliance.

Multiple stepwise regression analysis has been shown that the ASI is independently associated with ADMA plasma concentration, troponin concentration, T-chol level, LDL-chol concentration and hs-CRP in HD patients. Our data demonstrate that HD patients have higher levels of ADMA. The ADMA is an endogenous competitive inhibitor of NO synthase. The ADMA 
competes with $\mathrm{L}$-arginine. Therefore, NO levels decrease with increased ADMA levels. Recently, ADMA has been demonstrated to be a new and potentially independent marker of atherosclerosis and related cardiovascular disorders [28]. Endothelial dysfunction occurs when NO activity in the vascular tissue is decreased, resulting in decreased endothelium-dependent vasodilatation. ADMA is assumed to be a key regulator of $\mathrm{NO}$ synthase activity, notably of the endothelial NO synthase isoform. Thus, decreased NO activity might result in vasoconstriction and in that way increase aortic stiffness. To the best of our knowledge there are no data in the literature on ADMA concentration influence on aortic stiffness in patients with ESRD.

Accelerated vascular damage and defective vascular repair have been proposed as a mechanism for premature atherosclerosis and aortic stiffness, common findings among HD patients. Impairment of $\mathrm{NO}$ biosynthesis (e.g., by ADMA) or NO bioactivity (as with oxygenderived free radicals) causes endothelial vasodilatation dysfunction. Thereby, the correlations between ASI and oxygen-derived free radicals promoters such as Tchol, LDL-chol, hs-CRP, observed in the present study, were no surprised. The deleterious effects of T-chol, LDL-chol and hs-CRP in part a consequence of decreased availability of endothelium cells-derived NO, include smooth muscle proliferation, collagen synthesis, and deterioration of elastin which may impair arterial compliance [29]. Taken together, our findings suggest at least 2 pathways that could lead to increase of aortic stiffness in HD subjects: wall calcification and endothelium dysfunction.

The significant correlation was also detected between ASI and several parameters characterizing left ventricle function. This include correlation between ASI and parameters characterizing systolic function as ESS and $\mathrm{mFS} / \mathrm{ESS}$ and also between ASI and diastolic parameters: E/A ratio, IVRT and S/D ratio. We can only speculate about the mechanism linking aortic stiffness with left ventricle dysfunction. Loss of aortic wall compliance causes pressure elevation and abnormal pressure pattern that increases the afterload of the left ventricle. The result is development of left ventricle hypertrophy also strongly associated with aortic stiffness in studied groups.

\section{ASI and LAVI}

The most important finding of echocardiographic aspect of the study was the significant correlation between ASI and LAVI in patients with ESRD. In our study, we found for the first time that HD patients with higher aortic stiffness have greater LAVI. There are several explanations for such association. Firstly, hypertension which is a common among patients with renal failure. It is well known that aortic stiffness is associated with LA size in hypertensive patients [30]. Additionally other cardiovascular risk factors present in large number in HD patients also can influence aortic stiffness and it that way stimulate LA enlargement [31]. All of them can modify unfavorably of aortic intima-media structure and provoke loss of elastic properties. In the other hand these factors increase shear stress and stimulate endothelium dysfunction which was also proved by us by demonstrating elevated ADMA plasma level. In result aortic compliance became markedly deteriorated.

It is well known that increase of aortic stiffness predict the degree of left ventricular diastolic dysfunction [32]. The main feature of this clinical state is elevation of left ventricle diastolic pressure. Both greater values of LAVI and high NT-proBNP plasma concentration are markers of elevated enddiastolic pressure as well as pressure measured in LA [33,34].

\section{Conclusions}

The results of this study suggest, that aortic elastic properties are impaired in hemodialyzed patients. The levels of ADMA, T-chol, LDL-chol and hs-CRP may be a biomarkers or mediators of aortic stiffness in this clinical setting. Both LAVI and NT-proBNP concentration, signs of elevated left atrium pressure are markedly increased in hemodialyzed patients. The strong correlation between aortic stiffness index and LAVI, improved by association of specific biochemical markers with these echocardiographic indices, suggests, that there is the link between elastic properties of aorta and left atrium pressure in hemodialysed patients mediated by endothelial dysfunction.

\section{Limitations of the study}

The limitations of this study include its cross-sectional nature design with relatively small number of subjects. We do not investigate whether ASI still predict LAVI after adjustments for other significant co-variables including biochemical factors like NT-pro BNB, ADMA, cTnT. Finally, aortic stiffness may be influenced by clinical features that were not controlled in this study, eg. hypertension, diabetes, smoking etc. It remains to be determined whether these variables may alter presented association between aortic stiffness and LAVI in hemodialysed patients.

\section{Abbreviations}

HD: Hemodialysed patients; ESRD: End stage renal disease;

IVSSd: Interventricular endsystolic septum diameter; IVSDd: Interventricular septum enddiastolic diameter; PWSd: Posterior wall systolic diameter;

PWDd: Posterior wall diastolic diameter; LVEDd: Left ventricle enddiastolic diameter; LVESd: Left ventricle endsystolic diameter; LAmax: Left atrium maximal diameter; Aomax: Aortic maximal diameter; Aomin: Aortic minimal diameter; 4-CH: Four chamber; LAshort: Left atrium short diameter;

LAlong: Left atrium longitudinal diameter; LAS: Left atrium surface; LAC: Left 
atrium circumference; SV: Left ventricle stroke volume; SI: Stroke index; CO: Cardiac output; Cl: Cardiac index; EF: Ejection fraction; FS: Fractional shortening; LVM: Left ventricle mass; LVMI: Left ventricle mass index; ESS: Endsystolic stress; mFS: Midwall fractional shortening; LAV: Left atrium volume; LAVI: Left atrium volume index; ASI: Aortic stiffness index; E: Maximal velocity of early diastolic transmitral flow; A: Maximal velocity of late diastolic transmitral flow; IVRT: Isovolumetric relaxation time; S: Maximal systolic velocity in pulmonary veins; D: Maximal diastolic velocity in pulmonary veins; SBP: Systolic blood pressure; DBP: Diastolic blood pressure; MBP: Mean blood pressure; GFR: Glomerular filtration rate; hs-CRP: High sensivity C-reactive protein; T-chol: Total cholesterol; HDL-chol: HDL-cholesterol; TGC: Triglycerides; LDL-chol: LDL-cholesterol; MDRD: Modification of diet in renal disease (MDRD); CTnT: Cardiac troponin T; NT-proBNP: N-terminal fragment of brain natriuretic peptide; ADMA: Asymmetric dimethylarginine.

\section{Competing interests}

The authors declare that they have no competing interests.

\section{Author's contributions}

TZ - carried out echocardiography, conceived of the study, and participated in its design, and coordination, and wrote the manuscript. AW - participated in its design, and coordination, and approved the manuscript. AK conceived of the study, and participated in its design and coordination. AJ analyzed and interpreted data conceived of the study, and participated in its design and coordination. All authors read and approved the final manuscript.

\section{Author details}

${ }^{1}$ Chair and Department of Cardiology, Medical University of Lublin, Lublin, Poland. ${ }^{2}$ Chair and Department of Nephrology, Medical University of Lublin, Lublin, Poland. ${ }^{3}$ Chair and Department of Family Medicine, Medical University of Lublin, Lublin, Poland.

\section{Received: 11 June 2012 Accepted: 19 October 2012}

Published: 5 November 2012

\section{References}

1. Sarnak MJ, Levey AS, Schoolwerth AC, Coresh J, Culleton B, Hamm LL, McCullough PA, Kasiske BL, Kelepouris E, Klag MJ, Parfrey P, Pfeffer M, Raij L, Spinosa DJ, Wilson PW: Kidney disease as a risk factor for development of cardiovascular disease; a statement from the American Heart Association Councils on Kidney in Cardiovascular Disease, High Blood Pressure Research, Clinical Cardiology, and Epidemiology and Prevention. Circulation 2003, 108:2154-2169.

2. Rao AK, Djamali A, Korcarz CE, Aeschlimann SE, Wolff MR, Stein JH: Left atrial volume is associated with inflammation and atherosclerosis in patients with kidney disease. Echocardiography 2008, 25:264-269.

3. Tripepi G, Benedetto FA, Mallamaci F, Tripepi R, Malationo L, Zoccali C: Left atrial volume monitoring and cardiovascular risk in patients with end-stage renal disease: a prospective cohort study. J Am Soc Nephrol 2007, 18:1316-1322.

4. Eren M, Gorgulu S, Uslu N, Celik S, Dagdeviren B, Tezel T: Relation between aortic stiffness and left ventricular diastolic function in patients with hypertension, diabetes or both. Heart 2004, 90:37-43.

5. Laurent S, Boutouyrie P, Ama R, Gautier I, Laloux B, Guize L, Ducimetiere P, Benetos A: Aortic stiffness is an independent predictor of all-cause and cardiovascular mortality in hypertensive patients. Hypertension 2001, 37:1236-1241

6. Blacher J, Guérin AP, Pennier B, Marchais SJ, Safar ME, London GM: Impact of aortic stiffness on survival in end-stage renal disease. Circulation 1999, 99:2434-2439

7. Moncada S, Higgs A: The L-arginine-nitric oxide pathway. N Engl J Med 1993, 329:2002-2012.

8. Baylis C: Arginine, arginine analogs and nitric oxide production in chronic kidney disease. Nat Clin Pract Nephrol 2006, 2:209-220.

9. Patel M, Spertus J, Brindis R, Hendel R, Douglas P, Peterson E, Wolk M, Allen J, Raskin I: ACCF proposed method for evaluating the appropriateness of cardiovascular imaging. J Am Coll Cardiol 2005, 46:1606-1613

10. Stefanadis C, Stratos C, Boudoulas H, Kourouklis C, Toutouzas P: Distensibility of the ascending aorta: comparison of invasive and noninvasive techniques. Eur Heart J 1990, 11:990-996.
11. London GM, Pannier B, Guerin AP, Blacher J, Marchais SJ, Darne B, Metivier $F$, Adda $H$, Safar M: Alterations of left ventricular hypertrophy in and survival of patients receiving hemodialysis: follow-up of an interventional study. J Am Soc Nephrol 2001, 12:2759-2767.

12. Lang RM, Bierig M, Devereux RB, et al: Recommendations for chamber quantification: a report from the American Society of Echocardiography's guidelines and standards committee and the chamber quantification writing group, developed in conjunction with the European Society of Cardiology. J Am Soc Echocardiogr 2005, 18:1440-1463.

13. Rakowski H, Appleton C, Chan K: Canadian consensus recommendations for the measurement and reporting of diastolic dysfunction by echocardiography: from the Investigators of Consensus on Diastolic Dysfunction by Echocardiography. J Am Soc Echocardiogr 1996, 9:736-760.

14. Gehan EA, George SL: Estimation of human body surface area from height and weight. Cancer Chemother Rep 1970, 54:225-235.

15. Brennan SA: Statistical methods for assessing observer variability in clinical measures. BMJ 1992, 304:1491-1499.

16. Barberato $\mathrm{SH}$, Pecoits-Filho R: Prognosic value of left atrial volume index in hemodialysis patients. Arq Bras Cardiol 2007, 88:568-575.

17. Pritchett AM, Jacobsen SJ, Mahoney DW, Rodeheffer RJ, Bailey KR, Redfield MM: Left atrial volume as an index of left atrial size: a population-based study. J Am Coll Cardiol 2003, 41:1036-1043.

18. Tsang TS, Barnes ME, Gersh BJ, Bailey KR, Seward JB: Left atrium volume as a morphophysiologic expression of left ventricular diastolic dysfunction and relation to cardiovascular risk burden. Am J Cardiol 2002, 90:1284-1289.

19. Lang RM, Bierig M, Devereux RB, Flachskampf FA, Foster E, Pellikka PA, Picard MH, Roman MJ, Seward J, Shanewise J, Solomon S, Spencer KT, Sutton MSJ, Stewart W: Recommendations for chamber quantification. Eur J Echocardiogr 2006, 7:79-108

20. Fatema K, Bailey KR, Petty GW, Meissner I, Osranek M, Alsaileek AA, Khandheria BK, Tsang TS, Seward JB: Increased left atrial volume index: potent biomarker for first-ever ischemic stroke. Mayo Clin Proc 2008, 83:1107-1114.

21. Chan MY, Wong H-B, Ong H-Y Yeo T-C: Prognostic value of left atrial size in chronic kidney disease. Eur J Echocardiogr 1008, 9:736-740.

22. Tagore $\mathrm{R}$, Ling $\mathrm{LH}$, Yang $\mathrm{H}$, Daw H-Y, Chan $\mathrm{Y}-\mathrm{H}$, Sethi SK: Natiuretic peptides in chronic kidney disease. Clin J Am Soc Nephrol 2008, 3:1644-1651.

23. Vickery S, Price CP, John RI, Abbas NA, Webb MC, Kempson ME, Lamb EJ: B-type natriuretic peptide (BNP) and amino-terminal pro BNP in patients with CKD: relationship to renal function and left ventricular hypertrophy. Am J Kidney Dis 2005, 46:610-620.

24. Kim H, Jun D-W, Cho Y-K, Nam C-W, Han S-W, Hur S-H, Kim Y-N: The correlation of left atrial volume index to the level of N-terminal pro-BNP in heart failure with preserved ejection fraction. Echocardiography 2008, 25:961-967.

25. Bayes-Genis A, Vazquez R, Puig T, Fernandez-Palomeque C, Fabregat J, Bardaji A, Pascual-Figal D, Ordonez-Llanos J, Valdes M, Gabarrus A, Pavon R, Pastor L, Juanatey JRG, Almendral J, Fiol M, Nieto V, Macaya C, Cinca J, Bayes de Luna A for the MUSIC Study Group: Left atrial enlargement and NT-proBNP as a predictors of sudden cardiac deaths in patients with heart failure. Eur J Heart Failure 2007, 9:802-807.

26. van Kimmenade RR, Pinto $Y$, Januzzi J J Jr: When renal and cardiac insufficiencies intersect: is there a role for natriuretic peptide testing in the "cardio-renal syndrome"? Eur Heart J 2007, 28:2960-2961.

27. Zapolski T: Malnutrition-inflammation complex syndrome: link between end-stage renal disease, atherosclerosis and valvular calcification. Hypertens Res 2010, 33:541-543.

28. Schulze F, Lenzen H, Hanefeld C, Bartling A, Osterziel KJ, Goudeva L, Schmidt-Lucke C, Kusus M, Maas R, Schwedhelm E, Strödter D, Simon BC, Mügge A, Daniel WG, Tillmanns H, Maisch B, Streichert T, Böger RH: Asymmetric dimethylarginine is an independent risk factor for coronary heart disease: results from the multicenter Coronary Artery Risk Determination investigating the Influence of ADMA Concentration (CARDIAC) study. Am Heart J 2006, 152:493.

29. Lucke T, Kanzelmeyer N, Kemper MJ, et al: Developmental changes in the Larginine/ nitric oxide pathway from infancy to adulthood: plasma asymmetric dimethylarginine levels decrease with age. Clin Chem Lab Med 2007, 45:1525-1530. 
30. Lantelme P, Laurent S, Besnard C, Bricca G, Vincent M, Legedz L, Milon H: Arterial stiffness is associated with left atrial size in hypertensive patients. AECH. CardiovasC Dis 2008, 101:35-40.

31. Kylintireas I, Lazdam M, Bechar I, Cunnington C, Diesch J, Trevitt C, Francis JM, Neubauer S, Leeson P: Abstract 1320: Aortic stiffness is associated with left atrial volume in early adult life. Circulation 2009, 120:S477-S478.

32. Chung C-M, Chu C-M, Chang S-T, Cheng H-W, Yang T-Y, Wan P-C, Pan K-L, Lin Y-S, Hsu J-T: Quantification of aortic stiffness to predict the degree of left ventricular diastolic function. Am J Med Scienc 2010, 340:468-473.

33. Ammar KA, Jacobsen SJ, Mahoney DW, Kors JA, Redfield MM, Burnett JC, Rodeheffer RJ: Prevalence and prognostic significance of heart failure stages: Application of the American College of Cardiology/American Heart Association heart failure staging criteria in the community. Circulation 2007, 115:1563-1570.

34. Greenberg BH, Chatterjee K, Parmley W, Werner J, Holly A: The influence of left ventricular filling pressure on atrial contribution to cardiac output. Am Heart J 1979, 98:742-751.

doi:10.1186/1471-2261-12-100

Cite this article as: Zapolski et al:: Left atrial volume index and aortic stiffness index in adult hemodialysed patients - link between compliance and pressure mediated by endothelium dysfunction; a cross-sectional study. BMC Cardiovascular Disorders 2012 12:100.

\section{Submit your next manuscript to BioMed Central and take full advantage of:}

- Convenient online submission

- Thorough peer review

- No space constraints or color figure charges

- Immediate publication on acceptance

- Inclusion in PubMed, CAS, Scopus and Google Scholar

- Research which is freely available for redistribution 